\title{
PROPOSTA PRELIMINAR DE MAPEAMENTO GEOMORFOLÓGICO DA BACIA DO RIO SERIDÓ RN/PB.
}

\author{
GEOMORPHOLOGICAL MAPPING RIVER BASIN SERIDÓ RN/PB.
}

\author{
Rabelo $^{1}$, D. R.; Silva ${ }^{2}$, N. S. \\ dv_rr@hotmail.com;
}

\begin{abstract}
Resumo
O modo como a sociedade se apropria da natureza e de seus recursos naturais, modificando-a de acordo com seus interesses, faz com que esta mesma sociedade cause alguns impactos ao ambiente que é utilizado. A geomorfologia é um ramo da geografia física e estuda a evolução, descrição e análise do relevo, com isso servindo como base para os diversos planejamentos ambientais. A presente realizou um mapeamento geomorfológico da bacia hidrográfica do Rio Seridó com a finalidade de servir como planejamento ambiental e territorial da área. Foram utilizados produtos e softwares das geotecnologias, assim como revisões bibliográficas acerca do tema deste trabalho. Foram identificadas noves feições geomorfológicas divididas em dois grandes domínios morfoestruturais, com isso, analisadas e descrita essas feições. Portanto, o mapeamento geomorfológico auxilia no processo de análise territorial e ambiental dos municípios envolvidos em uma bacia hidrográfica.
\end{abstract}

Palavras-chave: Recursos naturais; Geografia física; Rio Seridó.

\begin{abstract}
The way society appropriates nature and its natural resources, modifying it according to their interests, makes this same society cause some impacts on the environment that is used. The geomorphology is a branch of physical geography and studies the evolution, description and analysis of relief, thus serving as the basis for the various environmental plans. This made a geomorphological mapping of the watershed of the Seridó River in order to serve as environmental and regional planning area. They were used products and software of geotechnologies, as well as literature reviews on the subject of this work. geomorphological features nines divided into two major areas morphostructural, therefore, analyzed and described these features were identified . Therefore, geomorphological mapping assists in the process of territorial and environmental analysis of the municipalities involved in a watershed
\end{abstract}

Keywords: Natural resources; Physical geography; Seridó River.

\section{INTRODUÇÃO}

Desde a antiguidade o ser humano se apropria dos recursos naturais para satisfazerem suas necessidades básicas. A civilização que ocupava as margens do rio Nilo produzia seu alimento e estabelecia uma relação com esse recurso natural. Esta relação até hoje vem sendo mantida, grandes centros urbanos se localizam nas margens dos rios, pés de serra, em cima da serra ou áreas litorâneas. No entanto, a ocupação sem o devido planejamento e respeitos aos recursos naturais, ocasiona em modificações significativa do ambiente natural.

A geomorfologia é um ramo da geografia física e uma ciência especifica que tem como analisar as formas do relevo, que constitui um importante subsidio para a apropriação devida do relevo como recurso natural e considerando a conversão das propriedades geoecológicas do ambiente (CASSETI, 2005 apud KÜGLER, 1976).

\footnotetext{
${ }^{I}$ Davi Rodrigues Rabelo, Programa de Desenvolvimento e Meio Ambiente - PRODEMA, Universidade Federal do Ceará - UFC, Fortaleza-CE, Brasil

${ }^{2}$ Nayara Santos da Silva, Pós-Graduação em Planejamento e Gestão Ambiental, Universidade Estadual do Ceará - UECE, Fortaleza-CE, Brasil
} 
Para Ross (1990) a geomorfologia é fundamental para as geociências, pois estão relacionados à caracterização do ambiente, além de descrever e diagnosticar as formas de relevo, a partir da identificação e compreensão dos processos morfogenéticos. O relevo assim, assume um papel importante para o planejamento urbano e ambiental no que diz respeito ao processo de ocupação do espaço, na qual as formas e estruturas da paisagem é interferida pela apropriação da sociedade.

Diante disso, a representação gráfica dos aspectos geomorfológicos de uma determinada área é representada por mapa, que tem a função primordial de apresentar de forma sintética e ilustrativa, as características e atributos relacionados as formas do relevo da determinada pesquisa. $\mathrm{O}$ mapeamento geomorfológico necessita preocupar-se com o reconhecimento das feições que ocorrem na área mapeada, reconhecer arranjos espaciais e as relações mutuas entre os sistemas (NOGUEIRA et al., 2008).

A área de estudo da presente pesquisa é a bacia hidrográfica do rio Seridó, que é a principal sub-bacia do rio Piranhas-Assu, localiza-se entre dois estados do nordeste brasileiro sendo Rio Grande do Norte e Paraíba (figura 01). A região do Seridó é dividida em duas partes, são elas: Seridó Ocidental e Oriental potiguar, e Seridó Ocidental e Oriental paraibano. A bacia do rio Seridó tem características geomorfológicas diferenciadas abrangendo um mosaico heterogêneo de feições geomorfológicas-geológica e degradação ambiental.

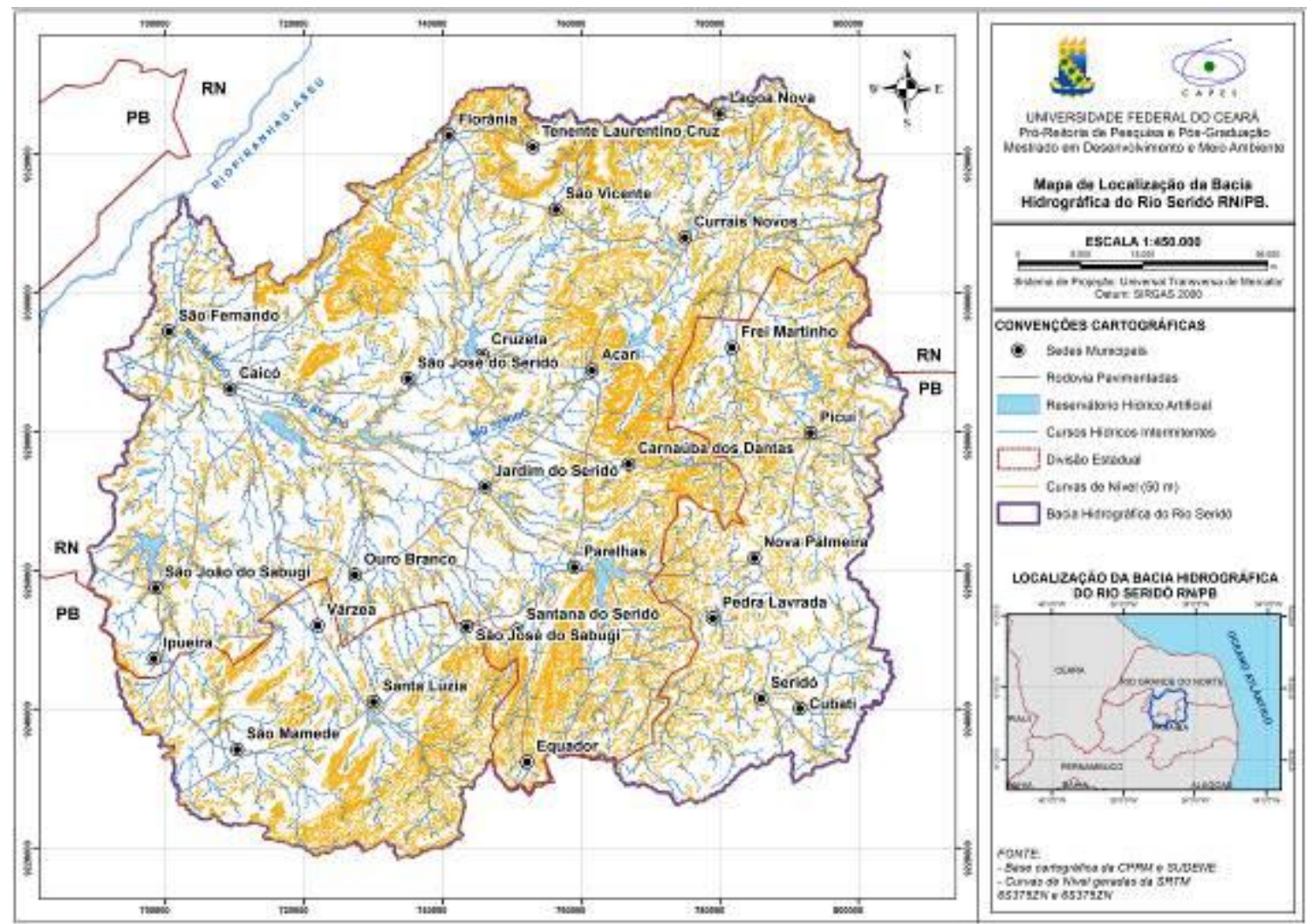

Figura 01. Mapa de localização da bacia hidrográfica do rio Seridó RN/PB. Fonte: autor (2016). 
Assim, o objetivo desse artigo foi elaborar um mapeamento geomorfológico da bacia do rio Seridó utilizando metodologias de identificação das formas de relevo, assim como utilizando as ferramentas do geoprocessamento e os produtos do sensoriamento remoto para a pesquisa.

\section{METODOLOGIA}

A pesquisa foi fundamentada empregando uma abordagem descritiva e qualitativa, tendo como base desde o conceito de bacia hidrográfica proposto por Christofoletti (1980), passando por Casseti (2005), adaptando a classificação e concepção geoambiental de Souza (2000) feito para o Ceará, categorização do relevo de Ross (1990) até o terceiro táxon e as explicações evolutiva geológica-geomorfológica de Jardim de Sá (1994).

Foram utilizados dados cartográficos e produtos do sensoriamento remoto para a delimitação da bacia hidrográfica do rio Seridó, assim como a extração da rede de drenagem e o mapeamento geomorfológico a partir de dados da Shuttle Radar Topography Mission (SRTM) obtidos por etapa de geoprocessamento.

Os dados cartográficos em formato shapefile foram obtidos a partir da disponibilidade do Companhia de Pesquisas de Recursos Minerais (CPRM) através do Geobank e atribuídos estes dados nos devidos mapas. Os produtos do sensoriamento remoto foram obtidos através do Instituto Nacional de Pesquisas Espaciais (INPE) com dados rasters da SRTM disponibilizados pelo site, sendo utilizado na presente pesquisa os rasters altimétricos 6S375ZN e 7S375ZN para então prosseguir no processamento desses dados.

Na delimitação da Bacia Hidrográfica e das drenagens do rio Seridó foram utilizados os seguintes comandos no software ArcGis 10: Fill - para correção das depressões do MNT; Flow Direction - avaliação de direção de fluxo; Flow Acumulation - cálculo do fluxo acumulado; Conditional - Con - delimitação dos rios; Snap Pour Point - definição do ponto de Exutório; Watershed - delimitação da bacia; Raster to Features - transformação para polígono.

Foi feito o mapeamento geomorfológico a partir dos dados da SRTM gerando desse produto, um subproduto que são as curvas de nível. Diante disso, esse subproduto foi interpolado para a geração do Triangulated Irregular Network (TIN) que é um modelo 3D digital do terreno.

Diante disso, a vetorização das feições geomorfológicas foi baseada nas expressões do relevo em virtude a sua altimetria, imagens Quickbird atuais disponibilizada pelo Google Eath Pro e mosaicadas pelo QGIS 2.0, e reconhecimento de campo. A escala do mapeamento foi adotada de 1:50.000 para que tenha uma melhor precisão da vetorização das planícies fluviais, no entanto, a escala cartográfica do mapa foi de 1:450.000 devido a área da bacia ter grandes dimensões, e por 
isso, o mapeamento consistiu até o terceiro táxon da categorização geomorfológica de Ross (1990). Além disso, a classificação das feições geomorfológicas foi utilizada e adaptada de Souza (2000) para a bacia do rio Seridó, na qual a partir dos grandes domínios naturais ele caracteriza as feições geomorfológicas através das condições geoambientais da região.

\section{RESULTADOS E DISCUSSÃO}

A partir da análise da forma e delimitação da bacia hidrográfica, assim como sua rede de drenagem, é notável que a distribuição das águas superficiais quando drenadas mostram a característica geológica e pedológica da região. Por ter grande parte da bacia encontrada em terrenos do embasamento cristalino e solos predominantemente mal drenados, sendo assim a drenagem caracterizada por dentritica.

Diante disso, a esculturação do relevo tem como fundamento a geomorfologia climática. As formas de relevo encontrados na bacia hidrográfica tem como base tanto os eventos climáticos quanto a estrutura litológica que os relevos possuem.

De acordo com o mapeamento (figura 02), foram identificadas nove feições geomorfológicas ao todo distribuídas em dois grandes domínios morfoestrutural que pertencem a primeira categorização de Ross (1990) são esses: Domínio dos Depósitos Sedimentares Cenozóicos e Domínio dos Escudos e Maciços Antigos. Ambos tiveram sua nomenclatura adaptada de Souza (2000) para a área de estudo.

Além disso, quatros feições morfoesculturais foram identificadas no segundo nível categórico de Ross (1990) e classificadas a partir da adaptação de nomenclatura de Souza (2000), são elas: planície fluvial, planalto sedimentar, depressão sertaneja e planalto cristalino da Borborema.

Por fim, as nove feições identificadas representam o terceiro nível categórico de Ross (1990) referente as unidades morfológicas ou padrões de forma semelhantes, são as feições: superfície de deposição; platô tabuliforme; escarpa dissecada; inselberg; morros residuais; serrotes e cristas residuais; superfície aplainada; platô, cristas e vales encaixados; baixas cristas e superfície dissecada. É notável que a diversificação das feições geomorfológicas mostra a relevância do estudo para o planejamento ambiental e urbano dos municípios da região do Seridó. 


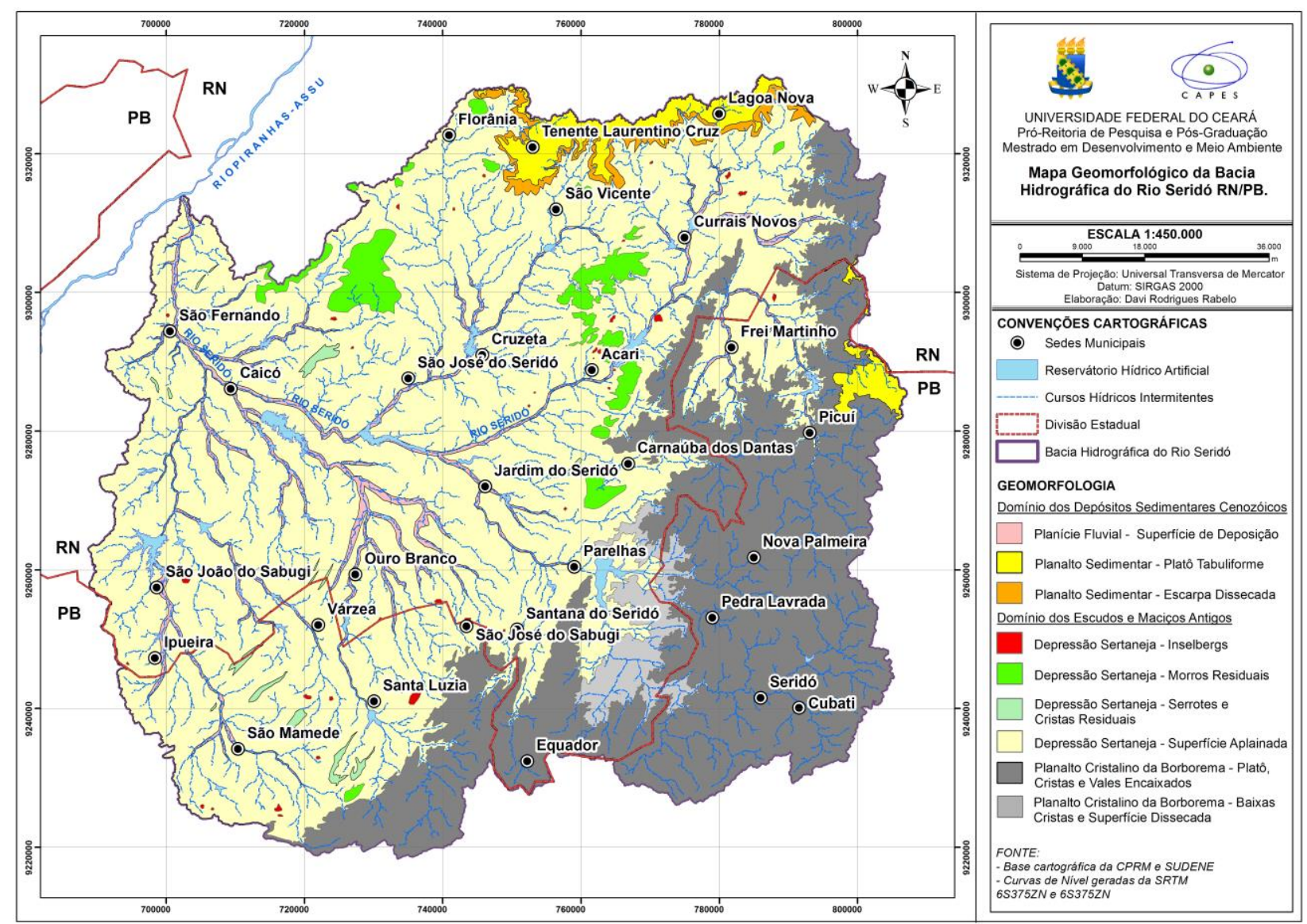

Figura 02. Mapa geomorfológico da bacia hidrográfica do rio Seridó RN/PB. Fonte: autor (2016)

De acordo com o mapa (figura 02), foram classificados as planícies fluviais e o planalto sedimentar como pertencente a grande morfoestrutura dos depósitos sedimentares cenozoicos classificados por Souza (2000) para o estado do Ceará e adaptado para o presente trabalho. Estas feições são caracterizadas pela ocorrência e evolução quaternária oriundas de processos de carreamento e deposição dos sedimentos provenientes da erosão nas rochas adjacentes.

A planície fluvial apresenta relevos planos acompanhando longitudinalmente os leitos dos rios e com característica de acumulação de sedimentos. As áreas da planície possuem diferenciação no semiárido brasileiro, proporcionando melhores condições de solo e disponibilidade hídrica (SOUZA, 2000). No entanto, essas condições só são encontradas nas áreas da depressão sertaneja, pois o poder de dissecação e erosão da drenagem não é forte, possibilitando a deposição. Nos altos cursos da bacia não são encontradas essas planícies devido ao poder de dissecação e transporte dos sedimentos. 


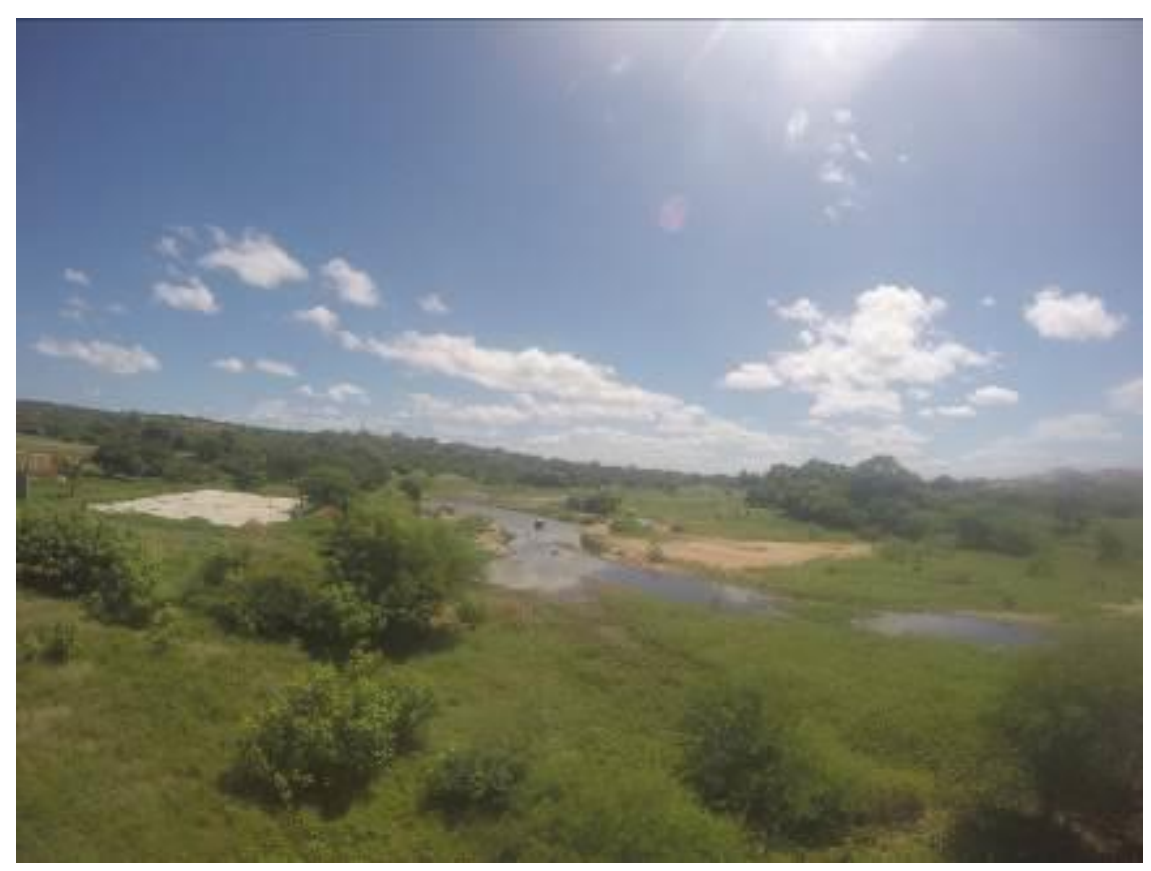

Figura 03. Rio Seridó e sua planície fluvial nas adjacências. Fonte: autor (2016)

Os planaltos sedimentares encontrados na região mostram uma característica diferenciada da região, sendo encontrada uma das áreas sedimentar em cima do planalto da Borborema e provando uma evolução geomorfológica um tanto polêmica quanto sua origem, que não é o objetivo do presente trabalho. Foi possível mapear essas grandes feições por causa de sua característica geomorfológica em forma de chapada. Esta característica diz respeito ao tipo de rocha que ela se encontra. No TIN a expressão do relevo plano fica notável, possibilitando assim, a identificação e o mapeamento desse relevo. Além disso, foi também identificado e mapeado a escarpa dissecada da Serra de Santana.

O Domínio dos Escudos e Maciços Antigos foi identificado no campo e delimitada suas feições a partir de suas características de relevo plano a suavemente plano no que se refere a depressão sertaneja, e os relevos com maiores declividades e dissecados em forma de " $\mathrm{v}$ " foram classificados como morros, serrotes e cristas residuais.

A depressão sertaneja foi a maior feição identificada com características altimétricas em torno de 150 m resultante de processos denudacionais oriundas dos processos de dinâmica erosiva durante principalmente as flutuações climáticas Cenozóicas, assim como, os maciços residuais identificados na área, oriundo dos processos de erosão diferencial e resistência litológica (SOUZA, 2000). 


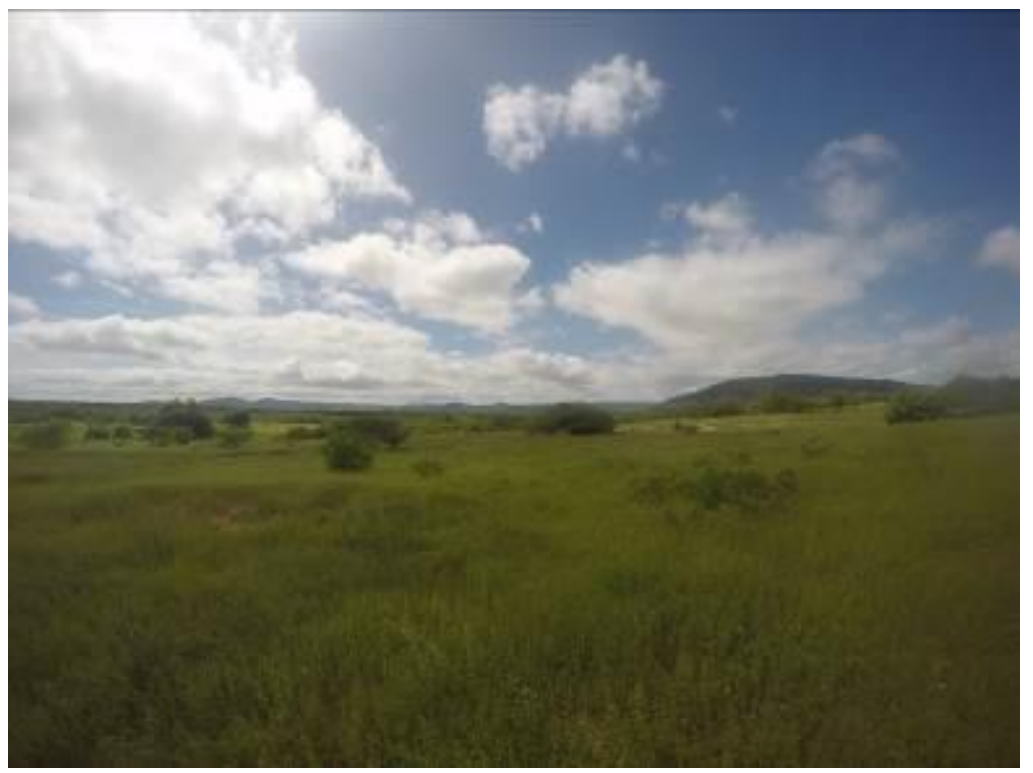

Figura 04. Em primeiro plano, depressão sertaneja e no segundo plano, planalto da borborema. Fonte: autor (2016)

$\mathrm{Na}$ área de estudo, há uma predominância do intemperismo físico caracterizado pela termoclastia com a variação de temperatura ao longo dos dias e noites e de diferentes épocas do ano, com isso, causando contração e expansão dos minerais desagregando assim blocos rochosos (TOLEDO, et al. 2003). Diante disso, uma das formas de resistência dos processos de aplainamento são os inselbergs e cristas residuais que diversificam a paisagem sertaneja e que foram mapeados de acordo com a escala.

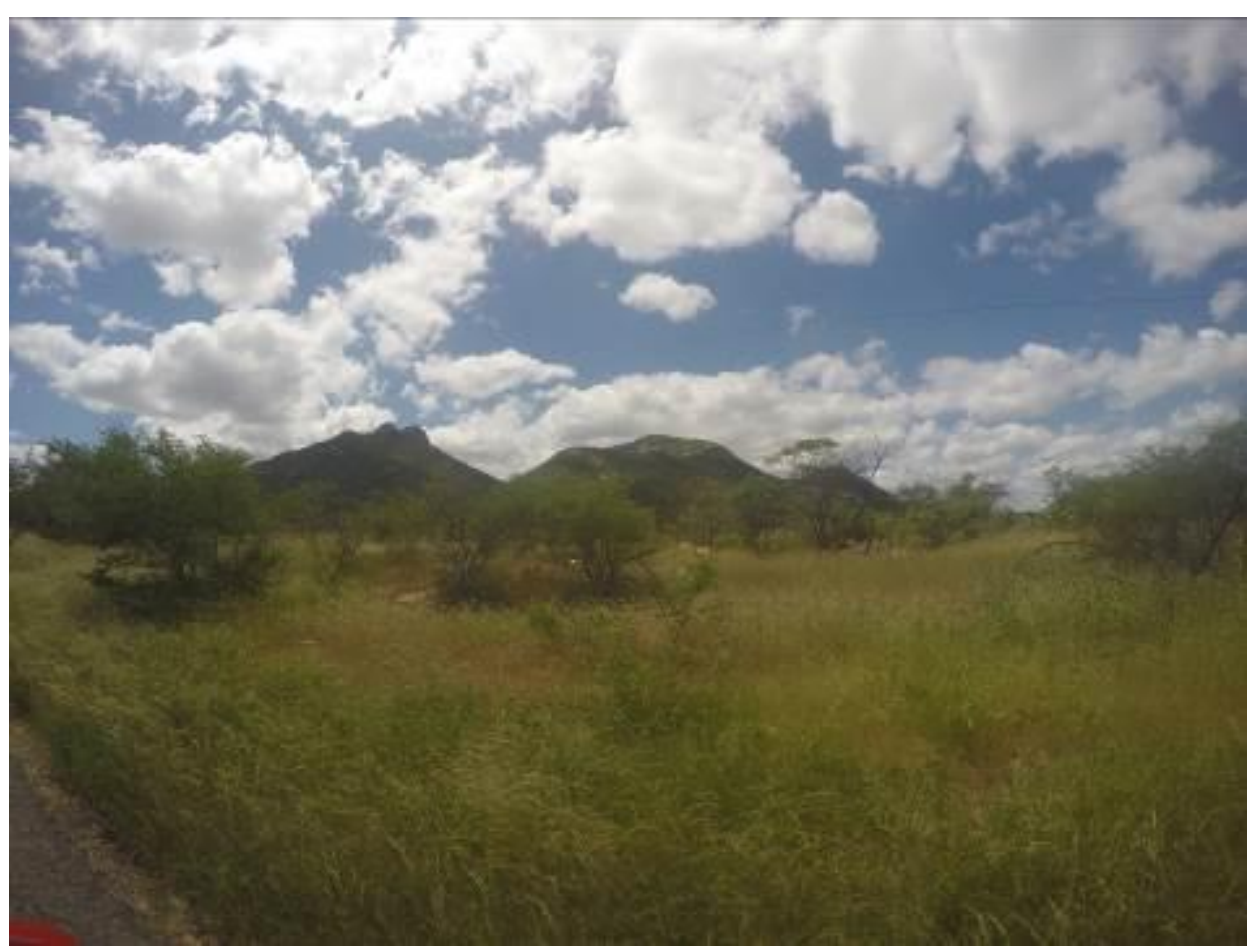

Figura 05. Em primeiro plano, depressão sertaneja e no segundo plano, pequeno maciço residual. Fonte: autor (2016) 
No planalto cristalino da Borborema na qual foram identificados platôs, cristas, vales encaixados e baixas cristas e superfície dissecada, em conjunto a área ocorre em uma altimetria em torno de 500 m e está associada sobre litologia metamórfica compondo maior abertura em relação a um conjunto de vales encaixados entre cristas residuais verificados em campo e no TIN. Diniz et al (2013) explica que essas cristas possuem topos elaborados em quartzitos com formas convexas apresentando feições tabuliforme nas suas periferias, mas ao passo que aprofundam o entalhamento quando se aproxima dos festonamentos da escapa ocidental, assumem formas em "v".

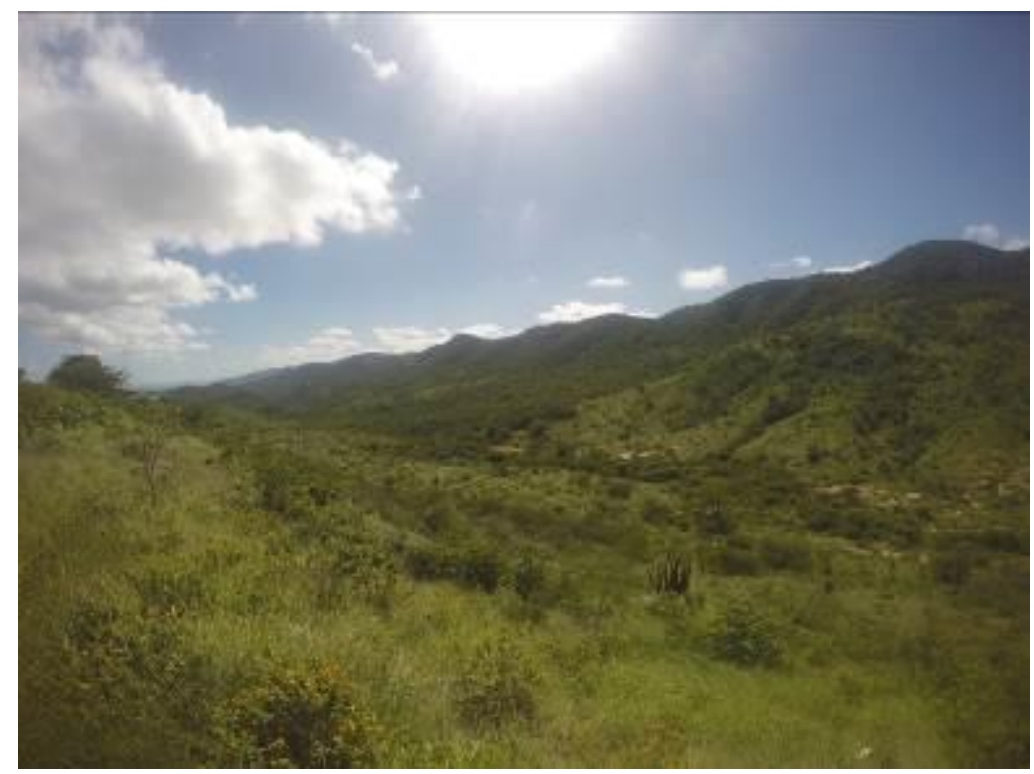

Figura 06. Conjunto de cristas residuais pertencentes ao planalto da Borborema. Fonte: autor (2016)

\section{CONSIDERAÇÕES FINAIS}

As formas de relevo servem como indicadores para uso e ocupação de uma determinada sociedade, com isso, o planejamento ambiental é necessário para que possa servir como subsídios para as diversas ocupações no território.

Na bacia do Rio Seridó foram identificadas várias formas de relevos, mostrando assim, uma diversidade geomorfológica na qual se encontra feições relacionadas as mais diferentes eras geológicas. O mapeamento buscou espacializar e representar as formas de relevo em suas dimensões, buscando a compreensão, análise e planejamento para essa área.

É valido que áreas mais declivosas tem um certo limite para o uso e ocupação em comparação áreas mais planas tendo em vista a dinâmica geomorfológica mais intensa como uma possível modificação dessas paisagens. Áreas na qual o solo é mais espesso e plano, compreendido por uma característica geológicageomorfológica sedimentar servindo como ajuda para os usos agrícolas. 
Portanto, a cartografia geomorfológica, assim como as geotecnologias, é de suma importância como ferramenta para auxílio de uma análise do relevo para diversos fins, sendo o planejamento ambiental para o presente trabalho.

\section{REFERÊNCIAS}

$\begin{array}{llll}\text { CASSETI, } & \text { Valter. } & \text { Geomorfologia. } & \text { [S.1.]: }\end{array}$ em: <http://www.funape.org.br/geomorfologia/>. Acesso em: 02/09/15

DINIZ, M.T.M; ALMEIDA, I.C.S; SILVA, S.D.R; PEREIRA, E.M. Pedologia e análise da paisagem: interações ambientais em Junco do Seridó/PB. Caderno Prudentino de Geografia, Presidente Prudente, n.35, v.1, p.90-111, jan./jul.2013.

KÜGLER, H. Zur Aufgaben der geomorphologischen Forschung und Kartierung in der DDR. Petermanns Geographische Mitteilungen, V. 120, n. 2, p. 154-160, 1976.

NOGUEIRA. T. C.; JÚNIOR. P. J. F.; S. C. RODRIGUES. Compartimentação morfológica com base em dados SRTM: estudo de caso bacia do rio Uberabinha, Uberlândia-MG. Rev. Geog. Acadêmica v.2 n.2 (VIII.2008) 154-169 ISSN 1678-7226 http://geograficaacademica.webng.com.

ROSS, J. L. S. Geomorfologia: Ambiente e Planejamento - (Coleção Repensando a Geografia). São Paulo, Ed. Contexto, 1990.

SOUZA, M. J. N.. Bases Naturais e Esboço do Zoneamento Geoambiental do Estado do Ceará in: LIMA, L. C., SOUZA, M. J. N., MORAES, J. O., Compartimentação territorial e gestão regional do Ceará. Fortaleza: FUNECE, 2000.

TOLEDO, M. C. M.; Oliveira, S. M. B.; Melfi. A. J. Intemperismo e Formação do Solo. Teixeira et al. (editores), Decifrando a Terra, 2a ed., Cap. 8, USP, São Paulo, 2003

Recebido em: 14/08/2016

Aceito para publicação em: 01/10/2016 